\title{
CONSIDERACIONES EN TORNO A LAS IMPLICACIONES METAFÍSICAS VIRGILIANAS EN GIORDANO BRUNO
}

\author{
DIEGO MOLGARAY ${ }^{1}$
}

\begin{abstract}
RESUMEN: El presente trabajo tiene como objetivo central dar cuenta del sentido que tiene la referencia al pasaje de la katábasis de Eneas, que se encuentra en Eneida VI 724-727, en aspectos metafísicos de la obra de Giordano Bruno. Para esto se tienen en cuenta dos objetivos previos: en primer lugar, analizando determinados pasajes de la obra de Virgilio, plantear la posibilidad de concebir una filosofía de Virgilio y, en segundo lugar, realizar un recorrido de la recepción y transformación del sentido en torno a Eneida VI 724-727 desde el siglo I hasta el XV con la intención de registrar hitos en la recepción de este pasaje hasta llegar a Giordano Bruno. Al analizar las obras de este autor en relación con el pasaje aludido, intentamos dar cuenta de su relevancia en la obra del nolano.
\end{abstract}

Palabras clave: Virgilio - Giordano Bruno - Eneida - mens - spiritus.

ABSTRACT. The central purpose of the present work is to give an account of the meaning of the reference to the passage of the katábasis of Aeneas, found in Aeneid VI 724-727, on metaphysical aspects of Giordano Bruno's work. To accomplish this, two previous objectives are taken into account: first, analyzing certain passages of Virgil's work, raising the possibility of conceiving a Virgilian philosophy and, secondly, making a journey on the reception and transformation of meaning around Aeneid VI 724-727 from the 1st to the 15th century in order to register milestones in the reception of this passage until reaching Giordano Bruno. When analyzing the works of this author in relation to the aforementioned passage, we try to account for its relevance in Nolan's work.

Keywords: Virgil - Giordano Bruno - Aeneid - mens - spiritus.

\footnotetext{
${ }^{1}$ UBA- E-mail: dmolgaray@ gmail.com

Fecha de recepción: 6/10/2021; fecha de aceptación: 8/11/2021.

DOI: https://doi.org/10.46553/sty.30.30.2021.p200-240
}

Stylos. 2021; 30 (30); pp. 200-240; ISSN: 0327-8859; E-ISSN: 2683-7900 
La obra de Giordano Bruno (1548-1600) se halla repleta de referencias a Virgilio (70 a.C.-19 a.C.). Estas son muy variadas: desde aquellas vinculadas al pedantismo humanista, pasando por la supuesta premonición de la conquista de América, ${ }^{2}$ hasta elementos centrales del pensamiento ontológico bruniano. En este sentido, nos interesa en el presente trabajo tomar en cuenta las referencias que Bruno hace a un pasaje clave de Eneida VI 726-727. Nos detendremos, en primer lugar, en los pasajes virgilianos de Bucólicas III 6061, así como en Geórgicas IV 219-222 y en Eneida VI 724-727 (siendo este último de particular relevancia para el desarrollo del resto de las concepciones), intentando dar cuenta del sentido de estas consideraciones para el mantuano. En segundo término, daremos cuenta brevemente de las diversas menciones a este pasaje de la Eneida a fin de mostrar someramente las metamorfosis que fue recibiendo, siempre con vistas a su recepción en Bruno. Luego nos detendremos en las referencias que hace a este pasaje el nolano en tres obras: De la causa, principio e uno (1584) y Lampas triginta statuarum (c. 1587) y De magia (c. 1590), e intentaremos dar cuenta del significado intrínseco a la filosofía de Bruno de estas referencias, y los desplazamientos de sentido que se dan en conceptos como mens, anima y spiritus. Por último, daremos cuenta de las conclusiones que podemos sacar de lo considerado.

\section{VIRGILIO}

En este primer apartado, nos detendremos en una consideración en torno a tres pasajes ${ }^{3}$ de cada una de las obras principales de Virgilio (no estamos

\footnotetext{
${ }^{2}$ A modo de indicación, podemos señalar el primer diálogo del De la causa, principio e uno (1584) como una polémica con el pedantismo humanista, así como el diálogo La cena delle ceneri (1584). A su vez, en Spaccio de la bestia trionfante (1584), podemos encontrar referencias a la cuarta égloga, en relación a vv. 34-36: "alter erit tum Tiphys et altera quae vehat Argo/ delectos heroas; erunt etiam altera bella / atque iterum ad Troiam magnus mittetur Achilles." Cf. GRANADA (2002).

${ }^{3}$ La selección de sólo tres pasajes nos obliga a dejar de lado pasajes sumamente relevantes para la discusión filosófica en Virgilio, como Bucólicas IV y VI, así como Geórgicas Proemio y final del libro II, y también Eneida IV, X y XII. Dada la exclusión de estos pasajes, debidas
}

Stylos. 2021; 30 (30); pp. 200-240; ISSN: 0327-8859; E-ISSN: 2683-7900 
tomando en cuenta la Appendix Vergiliana),${ }^{4}$ haciendo observaciones sobre el sentido filosófico que podemos extraer de ellos y, en último término, intentaremos dar respuesta a la pregunta acerca de la pertenencia filosófica del poeta mantuano.

\subsection{IOUVIS OMNIA PLENA: ¿NÚCLEO DE UN PENSAMIENTO PANTEÍSTA YA PRESENTE EN LAS BUCÓLICAS?}

En la tercera Bucólica, en el contexto de una competencia de verso entre Dámetas y Palemón, el primero da inicio al torneo de la siguiente manera:

(III, 60-61)

\begin{tabular}{l|l|}
\hline Ab Ioue principium Musae: & $\begin{array}{l}\text { En Júpiter principia mi Musa: todo } \\
\text { Iouvis omnia plena } \\
\text { Ille colit terras, illi mea carmi- } \\
\text { na curae. }\end{array}$ \\
$\begin{array}{l}\text { Él cultiva de Júpiter; } \\
\text { mis cantos. }\end{array}$ \\
\hline
\end{tabular}

En torno a este pasaje se han hecho múltiples observaciones. Notó Saunders ${ }^{6}$ la recurrencia del principio, que encontramos aquí referido en Ab Ioue principium Musae, que podremos relacionar con el pasaje de Eneida VI 724 más adelante (Principio caelum ac terras...), así como con numerosos otros pasajes de Virgilio. Lo que más nos interesa, no obstante, aquí es remarcar el énfasis que hace el poeta en lo que podemos caracterizar como panteísmo: todo es Dios, aquello que canta, aún el poeta bucólico, es Dios. En este sentido, nos detendremos a considerar el sentido de este pensamiento, para lo cual empezaremos por sus raíces estoicas.

a razones de espacio, nuestras conclusiones no pueden sino ser provisorias en pos de un futuro trabajo más abarcador.

${ }^{4}$ Respecto de este compendio de obras, no hay consenso respecto de su autoría.

${ }^{5}$ Excepto cuando sea específicamente indicado, en los textos latinos que citamos damos una traducción propia, intentando verter al castellano de la manera más literal posible, en atención a buscar el sentido filosófico de los términos utilizados.

${ }^{6}$ Cf. SAUNDERS (2008: 133).

Stylos. 2021; 30 (30); pp. 200-240; ISSN: 0327-8859; E-ISSN: 2683-7900 


\subsubsection{LA INFLUENCIA DEL PANTEÍSMO ESTOICO}

El pasaje aludido expresa una concepción filosófica que ha sido caracteriza$\mathrm{da}^{7}$ de índole estoica. En este sentido, nos interesa señalar los principales aspectos en que se expresó esta noción antes de Virgilio, para encontrarle un sentido más claro al sentido de este pasaje.

La concepción estoica es fuertemente panteísta y materialista. Dentro de esta concepción, la razón, que es, como caracteriza Cumont, ${ }^{8}$ un principio vital que mantiene y preserva al individuo, conectando sus diversas partes como alma del mundo, es la que gobierna lo cósmico. ${ }^{9}$

Veremos a continuación dos de las fuentes más probables para este pasaje. Nos interesaremos por marcar, especialmente en Arato, la marcada influencia filosófica del estoicismo, que estaría implícita en el pensamiento virgiliano.

\subsubsection{TEÓCRITO}

En primer lugar, la influencia más directa de este pasaje la encontramos, como suele suceder en esta obra, en Teócrito. ${ }^{10}$ Se trata de Idilios XVII.1:

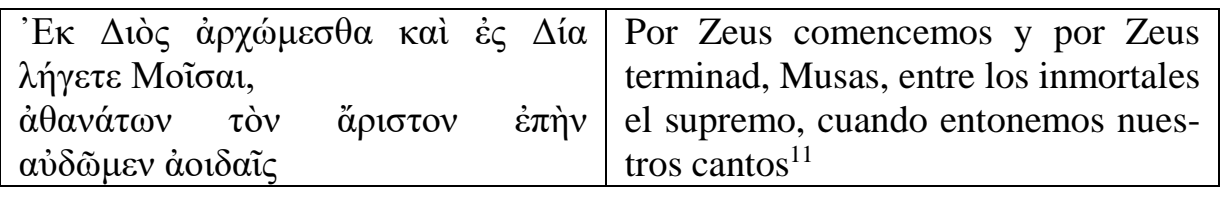

${ }^{7}$ Por ejemplo, JAMES (1972: 36).

${ }^{8}$ Cf. CumONT (1949: 114).

${ }^{9}$ Si bien hace énfasis en la influencia del orfismo, también BAUZÁ (2015: 252) afirma que Virgilio alude, por momentos, al estoicismo.

${ }^{10}$ Respecto de la recepción de Teócrito, GiESECKE (2000: 31) afirma que Virgilio fue el que no solo introdujo la pastoral teocrítea al repertorio de la poesía latina, sino que además lo hizo italiano.

11 TEÓCRITO (1986: 165-166).

Stylos. 2021; 30 (30); pp. 200-240; ISSN: 0327-8859; E-ISSN: 2683-7900 
La fórmula que da inicio a este idilio resulta sumamente similar al inicio de la competencia entre Dámetas y Palemón en Virgilio, así como el contexto pastoril, que da un marco común. A su vez, este texto es contemporáneo del próximo.

\subsubsection{ARATO}

La segunda fuente que encontramos para este pasaje es Arato, Fen. 1-2:

\begin{tabular}{|c|c|}
\hline 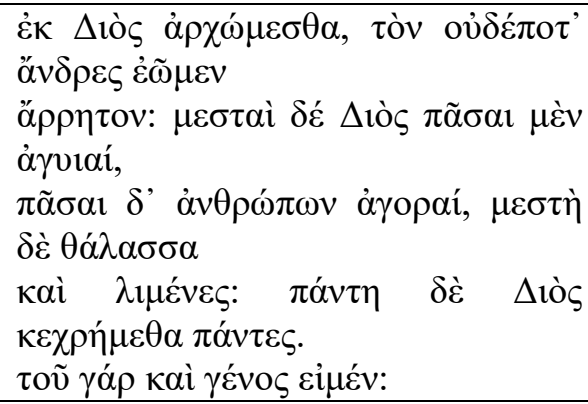 & $\begin{array}{l}\text { Comencemos por Zeus, a quien ja- } \\
\text { más los humanos dejemos sin nom- } \\
\text { bran. Llenos están de Zeus todos los } \\
\text { caminos, todas las asambleas de los } \\
\text { hombres, lleno está el mar y los puer- } \\
\text { tos. En todas las circunstancias, pues, } \\
\text { estamos todos necesitados de Zeus. } \\
\text { Pues también somos descendencia } \\
\text { suya. }{ }^{12}\end{array}$ \\
\hline
\end{tabular}

Este pasaje marca una influencia más marcadamente filosófica que en el caso citado de Teócrito, dado que aquí entra en juego la concepción estoica y su culto a Zeus, ${ }^{13}$ así como en el Himno a Zeus de Cleantes, si bien es menester observar que, mientras en el caso de Cleantes se halla en un marco estrictamente filosófico, con Arato nos encontramos una obra que, en palabras de James, puede caracterizarse como un tratado técnico versificado teñido de estoicismo. ${ }^{14}$ La expresión de Arato "el mundo está lleno de Zeus"

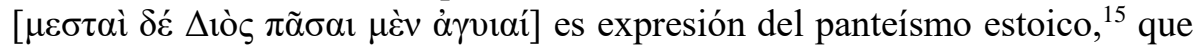
representa una tradición más antigua, que se remonta al himno órfico a Zeus. Esta noción parece estar vinculada, observa también James, a la noción es-

12 Arato (1993: 63).

${ }^{13}$ Cf. JAMES (1972: 36).

${ }^{14}$ Cf. JAMES (1972: 28).

${ }^{15}$ Cf. JAMES (1972: 36).

Stylos. 2021; 30 (30); pp. 200-240; ISSN: 0327-8859; E-ISSN: 2683-7900 
toica de $\pi \rho o ́ v o t \alpha$, es decir, la providencia, dado que, si Zeus está en todas partes, todo depende de él.

Dada la contemporaneidad de ambos textos (fueron publicados c. 270 a.C.), no parece claro si Arato hace aquí una referencia a Teócrito o es al revés. $^{16}$

\subsubsection{PROPÓSITO GENERAL DE LAS BUCÓLICAS}

Las Bucólicas constituyen la primera obra propiamente virgiliana, compuestas entre los años 43 y 39 a.C. ${ }^{17}$ Se trata de un conjunto de diez breves églogas, ordenadas según un criterio respecto del cual hay distintas consideraciones, aunque todos los comentadores comparten la idea de que no están ordenadas cronológicamente. ${ }^{18}$ En este sentido, podemos mencionar la hipótesis de Maury, ${ }^{19}$ según la cual estarían organizados en una terna pitagórica, que haría dialogar la I con la IX, la II con la VIII, la III con la VII, la IV con la VI y la V con la X. La ubicación de todas estas composiciones es Arcadia, el país de los pastores y de Pan, su dios, inventor de la siringa. Mientras su inspiración principal, los Idilios de Teócrito, se ubicaban en la Siracusa de la que éste era oriundo, Virgilio elige una Arcadia mítica, en la que puedan confluir la poesía pastoril y dioses y héroes míticos, un sitio a la vez alejado de la realidad cotidiana, pero ubicado en un campo mítico y con algunas referencias a los hechos de nuestro mundo. ${ }^{20}$

Teniendo, pues, presente el contexto general, nos queda ahora pensar brevemente el específico de este pasaje. Se da una competencia de canto entre los pastores Dámetas y Menalcas de canto amebeo, que se caracteriza porque el que responde debe usar la misma cantidad de versos que el prime-

\footnotetext{
${ }^{16}$ Cf. TEÓCRITO (1986: 166).

${ }^{17}$ Segura RAMOS (1997: 7).

${ }^{18}$ Cf. Segura Ramos (1997: 8), Ingberg (2004: 23),

${ }^{19}$ Cf. MAURY (1944: 71-147), citado en BAUZÁ (2015: 252).

${ }^{20}$ Cf. SNELL (1953: 281-283).
}

Stylos. 2021; 30 (30); pp. 200-240; ISSN: 0327-8859; E-ISSN: 2683-7900 
ro. ${ }^{21}$ Esta competencia, arbitrada por Palemón, y que comienza con el pasaje citado en labios de Dámetas, a cuya intervención responde Menalcas invocando a Febo, ${ }^{22}$ culmina en un empate.

\subsubsection{El SENTIDO DEL PASAJE EN EL CONTEXTO}

Nos interesa principalmente aquí la manera en que esto es acoplado por Virgilio a su cosmovisión. Si bien resulta un pasaje muy breve en el contexto de una diatriba que tiene allí su inicio, este breve pasaje de la tercera bucólica no queda abandonado, sino que encuentra en los demás pasajes aquí referidos -entre otros-, complementaciones. La divinidad, Júpiter [Iouvis], llena todo y lo hace (se verá más adelante) a través del actuar de una mente dentro del gran cuerpo (mens agitat molem et magno se corpore miscet, Eneida VI 727). A su vez, como observa Egil Kraggerud, ${ }^{23}$ Virgilio, en voz del pastor Dámetas, parece más insistente que Arato en aludir a Júpiter, dado que hace referencia a él en los cuatro dísticos (Iove, Iovis, ille, illi, tanto como nominativo, genitivo, dativo y ablativo). Además de remitir a Teócrito y Arato, este breve pasaje nos invita a considerar un posible marco metafísico en torno del cual el panteísmo funciona como marco referencial para todo lo que propone después. ${ }^{24}$

\footnotetext{
${ }^{21}$ Cabe observar que poco antes de iniciar esta competencia menciona a Orfeo como imagen en el trofeo del ganador de la contienda: "Orpheaque in medio posuit siluasque sequentis" (III, 46).

${ }^{22}$ Ecloga III 62-63: "Et me Phoebus amat; Phoebo sua semper apud me / munera sunt, lauri et suaue rubens hyacinthus."

${ }^{23}$ Cf. KRAGGERUd (2021: 318).

${ }^{24}$ En 1.4 indicaremos los reparos necesarios, no obstante, dado que es muy discutible plantear una "filosofía de Virgilio", de modo que nuestra lectura panteísta podría muy bien ser rebatida por lecturas que hagan acento, por ejemplo, en sus guiños a Lucrecio, por ejemplo.
}

Stylos. 2021; 30 (30); pp. 200-240; ISSN: 0327-8859; E-ISSN: 2683-7900 


\subsection{LAS ABEJAS Y LA MENTE DIVINA EN GEÓRGICAS}

Dentro de una breve digresión metafísica en el contexto del cuarto libro de las Geórgicas (cuya temática, en su primera mitad, está marcada por dar cuenta de los comportamientos de las abejas), encontramos el siguiente pasaje, que además nos anticipa el uso que dará en Eneida al vocablo mentis. Geórgicas IV 219-222:

\begin{tabular}{|l|l|}
\hline $\begin{array}{l}\text { His quidam signis atque haec } \\
\text { exempla secuti } \\
\text { esse apibus partem divinae mentis } \\
\text { et haustus }\end{array}$ & $\begin{array}{l}\text { Por estos signos y seguidos por es- } \\
\text { tos ejemplos } \\
\text { que eran las abejas parte de la men- } \\
\text { aetherios dixere; deum namque ire } \\
\text { per omnes } \\
\text { terrasque tractusque maris cae- } \\
\text { lumque profundum. }\end{array}$ \\
$\begin{array}{l}\text { etéreas se dijo; dado que dios atra- } \\
\text { viesa todas } \\
\text { las tierras y trechos del mar y cielo } \\
\text { profundo. } .^{25}\end{array}$ \\
\hline
\end{tabular}

En este pasaje, además de encontrar nuevamente la afirmación panteísta de que Dios atraviesa todo (denotados en una triple caracterización: tierras, mar y cielo ${ }^{26}$ ), vemos la caracterización de las abejas como parte de la mente divina, ${ }^{27}$ es decir, la vida de la naturaleza es parte de Dios, o al menos, de la mente de Dios. Nos interesaremos ahora en ver un poco más de cerca las fuentes de estas concepciones y su sentido en el contexto de esta obra. En el caso de la obra presente, existe una manifiesta importancia de la figura de Orfeo, reflejada en la narración de su historia al final del cuarto libro (Geórgicas IV 281-558). Por eso, intentaremos dar cuenta un poco de su influjo.

\footnotetext{
25 Intentamos verter de la forma más literal posible el pasaje, que podría, un poco más libremente, traducirse: "Por estos signos, y seguidos por estos ejemplos, se ha dicho que las abejas eran parte de la mente divina y emanaciones etéreas; dado que dios atraviesa todas las tierras y trechos del mar y cielo profundo".

${ }^{26}$ Cf. HARDIE (1986: 313-322).

${ }^{27}$ En el próximo apartado, 1.2.1., veremos la relación entre las abejas y el orfismo.
}

Stylos. 2021; 30 (30); pp. 200-240; ISSN: 0327-8859; E-ISSN: 2683-7900 


\subsubsection{LA INFLUENCIA DEL ORFISMO (1)}

Dar cuenta de las concepciones que conforman el orfismo es sumamente complejo. En este sentido, sólo podemos dar algunos rasgos característicos. ${ }^{28}$ Un evento teogónico que permite dar una caracterización general del orfismo es aquel episodio en que Zeus traga a Fanes/Protógonos para abarcar todo el universo, narración citada en un fragmento órfico que nos llega por Apuleyo. ${ }^{29} \mathrm{El}$ lugar de las abejas parece ser relevante dado que habrían emborrachado a Cronos, y en este sentido, los haustus aetherios podrían servir de referencia a estos tragos de los dioses. ${ }^{30}$

Como observa Bauzá, ${ }^{31}$ la imagen de Orfeo abre la primera bucólica (I 1-5) y cierra explícitamente la cuarta Geórgica (IV 467-527), dando inicio a fin a la obra que el poeta mantuano pretendió legar a la posterioridad. ${ }^{32}$

Independientemente de lo indeterminado en la trazabilidad del orfismo en Virgilio, la presencia de la imagen de las abejas en relación con las sugerencias de un panteísmo, y su vinculación inevitable con el final del libro IV de Geórgicas que narra el mito de Orfeo, nos colocan en la necesidad de tener en consideración esta perspectiva a la hora de leer estos pasajes y tratar de entender, en la medida de nuestras posibilidades, el sentido original del pensamiento virgiliano.

\footnotetext{
${ }^{28}$ Para ulteriores datos sobre el orfismo, podemos citar la obra clásica de BERNABÉ (2004), así como BAUZÁ (2015) y MACKENZIE (2019).

${ }^{29}$ Cf. MACKenZie (2019: 73). Podemos resumir el mito fundacional órfico de la siguiente manera: en un principio estaba la Noche $(N y x)$, (según algunas versiones acompañada por Tártaro) y ésta trajo un huevo del que surgió Fanes, Protógonos o Eros. Otra versión afirma que al principio estaba Cronos, de quien provenían Caos, Eter y Erebo, y Caos habría creado el huevo del Eter de donde habría surgido Fanes o Protógonos, un ser bisexual que habría tenido relaciones sexuales consigo mismo, dando inicio a la creación.

${ }^{30}$ Cf. MACKENZIE (2019: 73)

${ }^{31}$ Cf. BAUZÁ (2015: 258).

32 Dicho de otra manera: dado que Virgilio quiso legar a la posterioridad solo dos obras, el inicio de las Bucólicas y el fin de las Geórgicas parecen dar un marco vinculado al orfismo de toda la obra que Virgilio previó presentar como su corpus.
}

Stylos. 2021; 30 (30); pp. 200-240; ISSN: 0327-8859; E-ISSN: 2683-7900 


\subsubsection{PROPÓSITO GENERAL DE LAS GEÓRGICAS}

Las Geórgicas, la segunda obra de Virgilio, compuesta entre 37 y 30 a.C., ${ }^{33}$ con la idea general de una introducción en las labores de campo (tal vez sugerida por Mecenas, ${ }^{34}$ a la sazón ministro de Augusto, para incentivar el cultivo de tierras abandonadas), ${ }^{35}$ no obstante, se dedica más a diversas digresiones en torno a tópicos diversos poéticos, míticos y filosóficos. Si en el caso de las Bucólicas podemos dar como fuente principal ciertamente los Idilios de Teócrito, en el caso de las Geórgicas no bastaría indicar la fuente que implica Los trabajos y los días de Hesíodo, dado que se trata de una obra que aborda diversísimos temas con mayor detenimiento, y si bien ya encontrábamos algunas referencias antes, por caso, a Arato, ahora se trata de fuentes muy diversas, respecto de temas astronómicos, y rurales. De este modo, se destacan, entre las influencias en idioma griego, Historia de los animales de Aristóteles, Historia de las plantas de Teofrasto, las Teríacas, Geórgicas y Melisúrgicas de Nicandro, los Fenómenos de Arato, las obras astronómicas de Eratóstenes, y entre las obras latinas el De agricultura de Catón y Res Rustica de Varrón. ${ }^{36}$

\subsubsection{El SENTIDO DEL PASAJE EN SU CONTEXTO}

Dentro de una obra dedicada a las labores rurales, en el cuarto libro dedicado específicamente a los cuidados correspondientes a las abejas, y sobre todo al aspecto social de ellas, subraya el modo en que el individuo se somete e incluso sacrifica en pos del bien común. Es en el contexto de esta exaltación de la obediencia de las abejas a su rey que -señala- se dijo [dixere] que son par-

\footnotetext{
${ }^{33}$ Cf. Segura Ramos (1997: 13).

34 A diferencia de las Bucólicas, que no tienen una dedicatoria clara y expresa (puede considerarse que están dirigidas a Gayo Asinio Polión, a quien está dedicada la cuarta, pero no tienen una dedicación expresa en el conjunto como tal), en el caso de las Geórgicas sí hay una dedicatoria expresa a Mecenas, lo cual nos da un posible indicativo del instigador de la escritura de esta obra.

${ }^{35}$ Cf. Segura Ramos (1997: 13).

${ }^{36}$ Cf. Segura Ramos (1997: 14).
}

Stylos. 2021; 30 (30); pp. 200-240; ISSN: 0327-8859; E-ISSN: 2683-7900 
te de la mente divina [partem divinae mentis]. Y aquí realiza Virgilio una brevísima digresión metafísica en la que añade: deum namque ire per omnes I terrasque tractusque maris caelumque profundum, así pues, el dios ${ }^{37}$ atraviesa todo (la tierra, el mar y el cielo).

\subsection{SPIRITUS INTUS ALIT: EL CÉLEBRE PASAJE DE LA ENEIDA}

En la narración poético-filosófica que Anquises revela a su hijo Eneas en el contexto del descenso (katábasis) de su hijo a los Infiernos, nos encontramos la siguiente descripción:

Eneida VI 724-727

Principio caelum ac terras cam- Desde el principio, el cielo y la tierra posque liquentis lucentemque globum Lunae Titaniaque astra spiritus intus alit, totamque infusa per artus mens agitat molem et magno se corpore miscet. y las líquidas llanuras

Y el luciente globo de la luna y las estrellas titanias

El espíritu nutre desde dentro, difundida por las arterias

La mente mueve la mole y se mezcla al gran cuerpo.

Volvemos a encontrar aquí la recurrencia al vocablo (y el concepto que éste implica) principio. ${ }^{38}$ Observa Horsfall que esta palabra da una señal de lo que tratará, que no sólo será escatológico, filosófico, sino también expositivo. ${ }^{39}$ Con spiritus... mens se conforma, como observa Arundel, una expresión compuesta típicamente virgiliana. La expresión caelum ac terras camposque liquentis / lucentemque globum Lunae Titaniaque astra entra

\footnotetext{
${ }^{37}$ No podemos plantear aquí el problema que surgiría de cuestionarnos acerca de la identidad de este deum, si se trata de un proto-monoteísmo, o bien de una designación genérica de las divinidades politeístas.

${ }^{38}$ Como notábamos en 1.1 .

39 Cf. Horsfall (2013: 487). También hace referencia a que el inicio de Eneida "arma virumque cano" hace referencia a la Ilíada (arma) y Odisea (virum).
}

Stylos. 2021; 30 (30); pp. 200-240; ISSN: 0327-8859; E-ISSN: 2683-7900 
dentro de lo que Hardie califica como expresiones universales ${ }^{40}$ en la Enei$d a$, esto es, expresiones que intentan dar cuenta de la totalidad del mundo o del universo, distribuidas en dos o tres términos. En este caso, se trata de una expresión universal en tres términos: cielo, tierra y mares, completando con la luna y las estrellas, siguiendo el modelo de Ilíada XVIII 483, el pasaje donde se describe la confección del escudo de Aquiles:

\begin{tabular}{|c|c|}
\hline 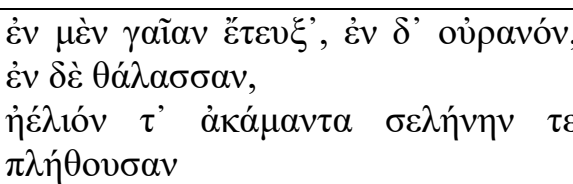 & $\begin{array}{l}\text { Hizo figurar en él la tierra, el cielo y } \\
\text { el mar, } \\
\text { El infatigable sol y la luna llena }{ }^{41}\end{array}$ \\
\hline
\end{tabular}

Así también, en De rerum natura II 1084-1086 encontramos el siguiente pasaje:

qua propter caelum simili ratione fatendumst

terramque et solem, lunam mare cetera quae sunt,

non esse unica, sed numero magis innumerali
Por esto, con una razón similar, hay que afirmar que el cielo y la tierra y el sol, la luna, el mar, (y) las restantes cosas que existen, no son únicos, sino (que son) más en un número sin medida; ${ }^{42}$

En relación a Titaniasque astra, observa Horsfall que es aún enigmático el uso de astra, es decir, estrellas en plural, en relación al sol ${ }^{43}$. Si solo se refiere al sol, puede entenderse el sol como hijo del titán Hiperión, pero esto no explica el plural astra. ${ }^{44}$ En torno a este epíteto, Giesecke lo relacio-

\footnotetext{
${ }^{40}$ HARDIE (1986: 293).

${ }^{41}$ HOMERO (2006: 379).

${ }^{42}$ LUCRECIO (2019: 325).

${ }^{43}$ Cf. Horsfall (2013: 488), existen referencias al sol como estrella en, por ejemplo, Cicerón, De natura deorum, 2.41, 92, 101-2

${ }^{44}$ Cf. Horsfall (2013: 488).
}

Stylos. 2021; 30 (30); pp. 200-240; ISSN: 0327-8859; E-ISSN: 2683-7900 
na con el lucreciano Arcadius sus (De rerum natura 5.25) y Lernea pestis (De rerum natura 5.26$).{ }^{45}$

La caracterización de la mens como infusa podría indicarnos que es algún tipo de líquido, ${ }^{46}$ y por tanto, penetra en el cuerpo, ocupándolo todo (totamque infusa). El uso de mens, por último, como sugería el pasaje de Geórgicas, hace referencia a un aspecto divino que se muestra en las cosas.

\subsubsection{LA INFLUENCIA DEL ORFISMO (2), DEL PITAGORISMO Y DEL PLATONISMO}

Encontramos ya en Williams, ${ }^{47}$ Norden,${ }^{48} \mathrm{y}$, más recientemente, Horsfall ${ }^{49} \mathrm{y}$ Mackenzie, ${ }^{50}$ la propuesta de que la Katábasis de Orfeo (OF 707-13) sea un modelo para la katábasis de Eneas. Horsfall señala, de hecho, que habría un texto órfico perdido el cual sería la base tanto para este texto como para el papiro de Bolonia (OF 717), que sería la base de Eneida VI 548-636. ${ }^{51}$ Este texto también podría haber inspirado la katábasis de Orfeo en las Geórgicas IV 474-484.

En los versos previos al discurso de Anquises nos encontramos algunas posibles referencias órficas, que dan cuenta del ambiente en el que el mantuano ubica este discurso. Así, en v. 645 hace referencia directamente al Threïcius (...) sacerdos, y en v. 707 aparecen nuevamente las abejas: velut in pratis ubi apes aestate serena / floribus insidunt variis, et candida circum / lilia funduntur. ${ }^{52}$

Conviviendo con estas consideraciones sobre el orfismo, no obstante, cabe observar que Courcelle señaló ${ }^{53}$ que la revelación de Anqusies a Eneas

${ }^{45}$ Cf. GiESECKE (2000: 71).

${ }^{46}$ Cf. Horsfall (2013: 489).

${ }^{47}$ Cf. Williams (1964: 49).

${ }^{48}$ Cf. NORDEN (1976: 5).

${ }^{49}$ Cf. Horsfall (2016: 26).

${ }^{50}$ Cf. MACKENZIE (2019: 68).

${ }^{51}$ Cf. BREMMER (2014: 59-60).

${ }^{52}$ Hicimos referencia a lo que implican las abejas en 1.2.1.

${ }^{53}$ Cf. COURCELLE (1984: 472).

Stylos. 2021; 30 (30); pp. 200-240; ISSN: 0327-8859; E-ISSN: 2683-7900 
consiste en una metafísica estoica impregnada de platonismo y pitagorismo ${ }^{54}$ mientras que Horsfall ${ }^{55}$ encuentra una procedencia estoica para el verbo agitat, que se remontaría a кıveĩ.

Giesecke encuentra en este pasaje resonancias del ciceroniano Somnium Scipionis 15, pero halla sobre todo un claro sabor lucreciano,${ }^{56}$ específicamente, la expresión camposque liquentis, que asocia con De rerum natura 5.488 camposque natantis y el comienzo del pasaje con De rerum natura 5.68-69:

\begin{tabular}{|l|l|}
\hline $\begin{array}{l}\text { fundarit terram caelum mare si- } \\
\text { dera solem } \\
\text { lunaique globum }\end{array}$ & $\begin{array}{l}\text { desarrolló la tierra, el cielo, el mar, los } \\
\text { astros, el sol } \\
\text { y el globo de la luna }\end{array}$ \\
\hline
\end{tabular}

Como observa Eve Adler, ${ }^{58}$ el discurso de Anquises respecto del principio de todo es anti lucreciano, una suerte de respuesta al discurso de Iopas que Eneas escuchó en la fiesta de Dido al final del libro 1. La enumeración de Anquises (cielo, tierra, océano) parece dejar fuera el inframundo. Y el planteo de la problemática respecto de la supervivencia de las almas y su posterior recompensa o castigo parece tener influencias platónicas.

\subsubsection{PROPÓSITO GENERAL DE LA ENEIDA}

La Eneida fue la última obra de Virgilio, cuya composición habría comenzado hacia 30 a.C., un año después de la victoria de Augusto en la batalla de Actium. ${ }^{59}$ A pesar de que el autor no quiso que fuera publicada, dado que no llegó a darle la última revisión, se convertiría en su obra más recordada y

\footnotetext{
${ }^{54}$ Remitimos en este aspecto a la discusión en 1.4 respecto de la dificultad que implica señalar una filiación filosófica para Virgilio. A su vez, BERNABÉ (2004: 137) señala lo arduo de distinguir tajantemente entre pitagorismo y orfismo.

${ }^{55}$ Cf. Horsfall (2013: 489). Remite, por ejemplo, al fragmento 135 de Zenón de Citio.

${ }^{56}$ Cf. GIESECKE (2000: 71).

${ }^{57}$ LUCRECIO (2019: 537).

${ }^{58}$ Cf. AdLER (2003: 295).

${ }^{59}$ Cf. GRANSDEN (2004: 1)
}

Stylos. 2021; 30 (30); pp. 200-240; ISSN: 0327-8859; E-ISSN: 2683-7900 
conocida. Si bien en el caso de esta obra encontramos una referencia clara en la épica homérica, particularmente en la Odisea (nombrada también por el héroe protagonista, y consistiendo su argumento en el viaje del héroe), cabe observar que mientras en el caso homérico consistió de una obra fuente para diversas obras posteriores, en el caso de la Eneida podemos decir que fue un repositorio en el que confluyeron diversas fuentes. Este enriquecimiento de la épica a partir de la Eneida provocó que a partir de entonces las demás obras de este género tuvieran también diversidad de fuentes, observa Harrison, un ejemplo de lo cual serían las Metamorfosis de Ovidio. ${ }^{60}$

\subsubsection{EL SENTIDO DEL PASAJE EN SU CONTEXTO}

En el sexto libro, encontramos la katábasis de Eneas, en la que se encuentra con su padre, Anquises en los Campos Elíseos. Este discurso se encuentra repleto de referencias a corrientes filosóficas y mitológicas. ${ }^{61}$ En este sentido, no sólo Odisea XI sirvió como fuente, sino también las obras platónicas Fedón, Gorgias, Fedro y República X, el Somnium Scipionis de Cicerón, los Anales de Ennio, entre otros. Esto nos permite observar la convergencia de diversas doctrinas en el discurso de Anquises: la supervivencia de las almas, el río Leteo, cierta doctrina del alma del mundo, confluencia de elementos platónicos, órficos, pitagóricos y estoicos.

\section{4. ¿PODEMOS HABLAR DE UNA FILOSOFÍA DE VIRGILIO?}

Luego de haber hecho estos repasos uno puede preguntarse, como han hecho diversos autores, cuál es, si se puede determinar tal, la filosofía que sostenía Virgilio. Respecto del interés virgiliano por la filosofía, sabemos, por la biografía de Elio Donato, de su interés por un retiro en Grecia o en Asia para

${ }^{60}$ Cf. HARrison (2007: 207-208).

${ }^{61}$ Cf. Williams (1964), Bremmer (2009), Horsfall (2013), Lotti (2019), entre otros numerosos textos en relación a las fuentes de este discurso.

Stylos. 2021; 30 (30); pp. 200-240; ISSN: 0327-8859; E-ISSN: 2683-7900 
dedicarse al estudio de la filosofía. ${ }^{62}$ Ahora bien, no disponemos de material certeramente virgiliano que nos permita contar con elementos de su pensamiento por fuera de sus tres grandes obras poéticas. En virtud de esta situación, podemos encontrar diversas posturas, y no pretendemos tener una respuesta acabada, sino tan solo recoger algunas consideraciones e intentar esbozar nuestras propias reflexiones. A continuación daremos, pues, algunos puntos de vista, que toman como base o bien aspectos biográficos, o bien el propio texto de las obras de Virgilio, para establecer conclusiones que inevitablemente llevan la marca de su emisor.

Antes de iniciar estas consideraciones, cabe observar, como nota Bernabé, que las diferencias entre órficos y pitagóricos son difíciles de establecer, tanto en relación a la precedencia de unos sobre otros, como en cuanto a la filiación de algunos textos en particular ${ }^{63}$. De este modo, estas distinciones padecen inevitablemente de un cierto rasgo de interpretación en cada caso.

Entre los elementos para considerar la filiación pitagórica de Virgilio, se ha señalado como una posible fuente a Nigidio Fígulo, un promotor del neopitagorismo del siglo I a.C. ${ }^{64}$ A su vez, además del referido trabajo de Maury que propuso un sentido pitagórico al orden de las Bucólicas, se ha observado que el número diez (la sumatoria de uno más dos más tres más cuatro) es un sello pitagórico, así como el dualismo que implica el que cada égloga requiera su complemento. ${ }^{65}$

Hugo Bauzá defiende el lugar del orfismo como "eje articulador" 66 en Virgilio. Así, la totalidad de la obra que Virgilio quiso fuera conocida por el público: Bucólicas y Geórgicas, comienza con una escena órfica y culmina con el mito de Orfeo y Eurídice ${ }^{67}$ No obstante, el mismo Bauzá observa que no corresponde entender a Virgilio como filósofo, sino como poeta; ${ }^{68}$ de este modo, las alusiones a diversas concepciones filosóficas deben entenderse todas como válidas y no mutuamente excluyentes. Así y todo, a su entender, el

\footnotetext{
${ }^{62}$ Mencionado en Morton Braund (1997: 205).

${ }^{63}$ Cf. BernabÉ (2004: 137-147).

${ }^{64}$ Cf. Alden SMith (2011: 42).

${ }^{65}$ Cf. Alden SMith (2011: 43).

${ }^{66}$ BAUZÁ (2015: 251).

${ }^{67}$ Cf. BAUZÁ (2015: 253-256).

${ }^{68}$ Cf. BAUZÁ (2015: 252).
}

Stylos. 2021; 30 (30); pp. 200-240; ISSN: 0327-8859; E-ISSN: 2683-7900 
orfismo ocupa un lugar central. De este modo, Bauzá, por ejemplo, sostiene ${ }^{69}$ que la poesía busca la natura naturans, es decir, la elevación al nivel supremo. Lo que desde una concepción analítica resulta muerto, vive en la poesía, en la unión que manifiesta la obra del poeta. Y es el poeta, señala Bauzá, el que realiza una mediación, descendiendo [katábasis] al alma del mundo para volver [anábasis] renovados. ${ }^{70}$

Entre los que defienden la postura de un Virgilio epicúreo, podemos mencionar el caso de Giesecke, quien considera ${ }^{71}$ directamente que Virgilio y Lucrecio compartieron la filosofía epicúrea, en parte apoyándose en pasajes, y en parte también del testimonio ${ }^{72}$ según el cual Virgilio habría estudiado, cuando tenía unos veinte años, con el epicúreo Siro, en Nápoles. Sin embargo, esto no quita que existan sutiles alteraciones, en pos de adaptar las ideas lucrecianas en un marco propio. ${ }^{73}$ Eve Adler ${ }^{74}$ afirma que Virgilio adhiere al materialismo lucreciano, pero, dado que considera que la vida humana no podría subsistir sin la creencia en la providencia y en dioses que castiguen las malas obras, por lo que intenta rectificar la presentación de la filosofía lucreciana en su propio orden cosmológico. Hardie ${ }^{75}$ por su parte, afirma que Virgilio fue epicúreo en su juventud, y que la obra de Lucrecio lo marcó tanto que lo llevó a escribir toda su obra en hexámetros y siempre tuvo simpatía por su doctrina moral, aunque haya sufrido luego una reconversión por la que se distinguió en las doctrinas físicas y teológicas. A su vez, la superioridad de Virgilio sobre Lucrecio, afirma Hardie, según el propio mantuano, estaría en que no se dedica a la investigación de la naturaleza, sino al canto de las selvas. ${ }^{76}$

\footnotetext{
${ }^{69}$ Cf. BAUZÁ (2015: 256).
}

${ }^{70}$ Remite, en este contexto, Bauzá, a las Cartas a un joven poeta de Rilke, así como sus Sonetos a Orfeo.

${ }^{71}$ Cf. GIESECKE (2000: 32).

${ }^{72}$ Hace referencia a Catalepton 5 y 8, obras de las que reconoce la improbable autenticidad, no obstante lo cual, le otorga valor como documento en relación a la temprana vida de Virgilio.

${ }^{73}$ Cf. GieseCKe (2000: 33).

${ }^{74}$ Cf. ADLER (2003: x-xi).

${ }^{75}$ Cf. HARDIE (1986: 157).

${ }^{76}$ Cf. HARDIE (1986: 34). Con respecto al pasaje referido de Geórgicas, Cf. III 475-502.

Stylos. 2021; 30 (30); pp. 200-240; ISSN: 0327-8859; E-ISSN: 2683-7900 
Por su parte, Horsfall afirma ${ }^{77}$ que Virgilio fue un maestro del bricoleur, formando capas y capas de diversas fuentes, en un estilo que consiste en amalgamar diferentes autores, de modo que no sería propio hablar de una filosofía de Virgilio. Esta situación del bricoleur podríamos emparentarla con la que nos ofrece Morton Braund, quien encuentra en la obra de Virgilio elementos epicúreos, estoicos, neoplatónicos, neopitagóricos, así como imágenes apocalípticas del cercano Oriente. ${ }^{78}$ Esta diversidad de perspectivas, observa Morton Braund, se debe en parte al contexto en que se encontraba el pensamiento de la elite romana, que se centraba en la recepción de la filosofía helenística, centralmente a través de Cicerón y, sobre todo, Lucrecio, que tradujeron esos conceptos filosóficos a la terminología latina, y en este sentido no debe perderse de vista que Virgilio se veía a sí mismo como romano, no como griego, y por tanto difícilmente se identificaría por completo con una vertiente filosófica determinada; así pues, la postura de esta autora es considerar la función de las ideas en cada contexto, en lugar de buscar la filiación de cada idea. ${ }^{79}$

Por nuestra parte, consideramos que se puede establecer, si no una doctrina filosófica explicitada por Virgilio, sí unos presupuestos filosóficos en la base de su poesía. Veíamos en el pasaje de Bucólicas III 60-61 la divinidad llena todo, a través de una mente [mens] que mueve [agitat] la mole [molem] y se mezcla [se miscet] al gran cuerpo [magno corpore]. Ahora bien, esta incorporación de la noción de mens, molem, magno corpore nos lleva a realizar unas pocas consideraciones. En primer lugar, la distinción dualista, dentro de un contexto de una metafísica panteísta (según tenemos por la tercera bucólica), entre mente y cuerpo o mole. Este dualismo nos permitirá ver cómo será tomado en obras posteriores, que lo asimilarán a la distinción espíritu (o alma) / materia, llegando a realizar lecturas más cercanas a la teología cristiana, y otras más cercanas a posturas panteístas.

\footnotetext{
${ }^{77}$ Cf. Horsfall (2016: 2).

${ }^{78}$ Un sentido para la diversidad de pensamientos virgilianos en el contexto de su obra poética puede ser dado por la observación de Servio a Eneida X 467, donde nota "Sectis philosophorum poetae pro qualitate negotiorum semper utuntur" (citado en MORTON BRAUND 1997: 206), esto es, los poetas explotan diversas sectas filosóficas en virtud del contexto.

${ }^{79}$ Cf. MorTON BRAund (1997: 207).
}

Stylos. 2021; 30 (30); pp. 200-240; ISSN: 0327-8859; E-ISSN: 2683-7900 


\section{RECEPCIÓN DEL PASAJE VIRGILIANO EN LA TRADICIÓN}

Nos dedicaremos ahora a realizar una breve ${ }^{80}$ consideración en torno a la recepción de este último pasaje en particular en diversos autores en los siglos siguientes. Considerar, aun brevemente, estas recepciones nos permitirá comprender la forma en que será recibido por Giordano Bruno, cuando abordemos esa cuestión en el siguiente apartado. No pretendemos llevar realizar un estudio exhaustivo de este recorrido, sino hacer las referencias que consideramos más significativas en el recorrido desde Virgilio hasta Giordano Bruno. ${ }^{81}$

Una de las primeras recepciones de este pasaje la podemos encontrar ya en Minucio Felix (150-270), un apologista romano del cristianismo preniceno. Nos interesa hacer hincapié en que ya aquí se asocia la concepción

${ }^{80}$ Corresponde que insistamos aquí en el adjetivo "breve", dado que la cuestión de una historia de la tradición de este pasaje virgiliano hasta Bruno merecería una investigación independiente. No obstante, nos interesa aquí al menos detenernos en algunos hitos dado que consideramos que esto resulta fundamental para dar lugar a la transformación que recibe el pasaje a lo largo de los siglos de interpretación, imposible de resumir en estas líneas, y sin embargo intentamos dar cuenta, al menos brevemente, de esto. Un listado de autores que intervino en esta recepción podría incluir a los siguientes autores: Macrobio, Minucio Felix, Claudio Mamertino, Lactancio, Paulino de Nola, Ambrosio de Milán, Cirilo de Alejandría, Jerónimo de Estridón, Prudencio, Draconcio, Escoto Eriúgena, Pedro Abelardo, Guillermo de Conches, Cristóforo Landino, Marsilio Ficino, Cornelio Agrippa, Agostino Steuco, Giordano Bruno. A su vez, la historia de la recepción podría continuar con autores posteriores, como Francis Bacon, René Descartes, Ralph Cudworth, entre otros; al respecto, Cf. LOTTI (2019), entre los casos podemos destacar el de Newton, que en el comentario a las proposiciones IVIX del tercer libro de sus Principia vincula la fuerza de gravedad con este pasaje virgiliana y su recepción en Macrobio (Cf. LOTTI 2019: 153).

${ }^{81}$ En torno a esta recepción, nos referiremos a tres principales vías: a) la obra de 1984 de COURCELLE (1984: 472 ss), constituirá nuestra principal fuente en torno a la recepción en general de este pasaje; b) el artículo de AlBANESE (2000), que organiza lo que denomina interpretatio platonica de los versos de Virgilio, Eneida VI 724-727 en torno a diversos autores hasta llegar a Bruno y c) el artículo de GRANADA (1983) que busca establecer la forma en que el humanismo renacentista (Petrarca, Salutati, Bruni, Boccaccio, entre otros) retornaron a la theologia poetica que había quedado dejada de lado con el reingreso del aristotelismo en el siglo XII, y que uno puede encontrar tanto en el pasaje de Eneida como en la cuarta égloga.

Stylos. 2021; 30 (30); pp. 200-240; ISSN: 0327-8859; E-ISSN: 2683-7900 
de una inteligencia que anima el mundo como una profesión de fe monoteísta. ${ }^{82}$ Aleja ya el texto del contexto original, del siglo I a.C., para llevarlo a un contexto cristiano. En este sentido, tenemos el pasaje en Octauius, XIX, 1:

Mantuanus Maro nonne apertius proximius uerius: 'Principio', ait, 'caelum ac terras' et cetera mundi membra 'spiritus intus alit' et 'infusa... mens agitat' (...) Idem alio loco mentem istam et spiritum deum nominat. (...)

Quid aliud et a nobis Deus, quam mens et ratio et spiritus praedicatur?"
El poeta de Mantua, Marón, ¿no dice
en términos más directos,
aproximados, verdaderos, que 'en el
principio, el cielo y la tierra' y todas
las demás partes del mundo están
'alimentadas desde dentro por un
espíritu' (...) Además, en otra parte,
llama a esta inteligencia y a este
espíritu Dios (...)
¿Pero no proclamamos nosotros
también que Dios no es más que
mente razón yespírtu? mente, razón y espíritu?

Nos interesa destacar aquí dos acciones que realiza Minucio Felix con el pasaje virgiliano: a) asimilar a su propia doctrina (cristiana) el pasaje de Eneida VI; b) asociar la noción deum virgiliana a lo que Minucio Felix llama Deus. Es decir, dos siglos después de su composición, ya vemos asimilados estos pasajes a la concepción temprano-cristiana. Si bien no parece haber una conexión directa con el pensamiento bruniano, es interesante destacar aquí también la asociación a Deus de mens y spiritus, conceptos que veremos aparecer nuevamente en Bruno.

En el Commentariorum in Somnium Scipionis liber primus et secundus, realizado por Macrobio (fl. c. 400 d.C.) en relación con un pasaje final del De Re Publica ciceroniano, encontramos lo que podemos caracterizar como la primera recepción de este pasaje dentro de un contexto neoplatónico pagano. El pasaje que nos interesa es el siguiente: $(14,14)$

${ }^{82}$ Cf. CourCelle (1984: 472).

Stylos. 2021; 30 (30); pp. 200-240; ISSN: 0327-8859; E-ISSN: 2683-7900 
hunc rerum ordinem et Vergilius También Virgilio reprodujo esta expressit. nam et mundo animam clasificación. Pues, también él dedit et, ut puritati eius attestaretur, atribuyó al mundo un alma, y para mentem vocavit. dar testimonio a favor de su pureza, la llamó mente. ${ }^{83}$

A su vez, Servio (363 - s. IV o V), en In Vergilii Aeneidem commentarii, señalaba en relación a este pasaje:

et unum est sive mentem dicat, sive $\mathrm{Y}$ uno fue dicho la mente, o alma o \begin{tabular}{l|l} 
animum, sive spiritum & espíritu
\end{tabular}

En estos pasajes encontramos ubicación de los conceptos de spiritus y mens virgilianos, en el caso de Minucio Felix, con el Dios cristiano, y en el caso de Macrobio y Servio, con el anima mundi platónica. ${ }^{84}$

Dentro de la tradición cristiana, se desarrolla una suerte de concordancia de la noción platónica de alma del mundo (Timeo 35a-b, Leyes X 896e), cierta concepción aristotélica (De caelo II 12 292a-20-22, Metafísica XII 8 1073a 14-1074a) y plotiniana (Enéadas II 1 15; II 3 17) con las Escrituras (Génesis 1,2). Dentro de esta adaptación sincrética, en obras como De Genesi ad litteram y De consensu evangelistarum de Agustín de Hipona y en De Spirito Sancto y los sermones sobre el Hexameron de Basilio de Cesarea, así como en Contra Julianum de Cirilo de Alejandría, podemos también encontrar obras que incorporan la perspectiva de la

\footnotetext{
${ }^{83}$ MACROBio (2006: 240).

${ }^{84}$ Decimos "platónica" en un sentido general: no hay certeza sobre la lectura que Macrobio en particular realizara de Platón y Plotino. Podemos, en este sentido, señalar que existe un debate entre comentadores como CumONT (1919), quien defiende la postura de que Macrobio leyó comentarios de Porfirio, y jamás directamente las obras de Platón y Plotino, mientras MrAS (1933), por ejemplo, asegura que tuvo acceso directo a Platón y Porfirio. Más allá de las posibles distinciones conceptuales entre Platón, Plotino, Porfirio, e incluso Cicerón, consideramos oportuno señalar unos ciertos rasgos comunes del concepto de alma que es el asociado en este caso con los conceptos virgilianos de spiritus y mens.
}

Stylos. 2021; 30 (30); pp. 200-240; ISSN: 0327-8859; E-ISSN: 2683-7900 
Eneida, como por ejemplo el De Spirito Sancto de Ambrosio de Milán ${ }^{85}$ y el In Isaiam de Jerónimo de Estridón, donde se lo vincula con los estoicos. ${ }^{86}$

Aproximándonos cronológicamente a Bruno, en el Renacimiento destacamos dos casos de recepción de este pasaje. De un lado, podemos citar, en primer lugar, un pasaje perteneciente a De vita (1489) de Marsilio Ficino (1433-1499), y en segundo, uno que corresponde a De occulta philosophia (1533) de Cornelio Agrippa (1486-1535). En ambos casos se trata de autores cercanos a Giordano Bruno, citados numerosas veces por él,y por tanto, testamento del modo en que llega al nolano el pasaje de Eneida VI 724-727. El siguientes es el pasaje en De vita, III, 3, 24-42:

Sed ad mundi spiritum redeamus, per quem mundus generat omnia (...) Ipse vero ubique viget in omnibus generationis omnis proximus auctor atque motus, de quo ille: "Spiritus intus alit." Totus est suapte natura lucidus calidusque et humidus atque vivificus, ex dotibus animae superioribus dotes eiusmodi nactus.
Pero volvamos al espíritu del mundo, por cuyo medio genera el mundo todo (...) Este está presente en todas partes y en todo, es el autor próximo a toda generación y movimiento, y a esto se refiere [el poeta]: «El espíritu nutre desde dentro». En virtud de su naturaleza es totalmente cálido, resplandeciente y húmedo y vivificante; ha adquirido estas cualidades a partir de las dotes superiores del alma.

\footnotetext{
${ }^{85}$ Cf. De Spirito Sancto V 36: "Gentiles homines per umbram quamdam nostros secuti, quia veritatem Spiritus haurire non poterant; quod coelum ac terras, lunae quoque stellarumque micantium globos Spiritus intus alat, suis versibus indiderunt.”. Cf. AlbANESE (2000: 184). En este pasaje, Virgilio es visto como un pagano que pudo ver "a través de cierta sombra" [per umbram quamdam], la verdad del Espíritu [veritatem Spiritus].

${ }^{86}$ Cf. In Isaiam LVII 49: "Quidam nostrorum hunc esse aiunt spiritum, quo omnis mundus inspiratur et regitur; et cuncta habent notitiam Dei, quem iuxta Stoicos insignis poeta scribens, ait (Virgil. VI Aeneid.): Principio coelum ac terras camposque liquentes, Lucentemque globum lunae, Titaniaque astra Spiritus intus alit: totamque infusa per artus, Mens agitat molem, et magno se corpore miscet. et reliqua." Cf. ALBANESE (2000: 184-185), GREGORY (2006: 526). Aquí, lo presenta Jerónimo como un "insigne poeta estoico" [Stoicos insignis poeta] que tiene un "conocimiento de Dios" [notitiam Dei].
}

Stylos. 2021; 30 (30); pp. 200-240; ISSN: 0327-8859; E-ISSN: 2683-7900 
Vemos aquí el rol que juega el concepto de spiritus en Ficino: autor de toda generación y movimiento, el espíritu del mundo moviliza lo que existe desde dentro. Veremos en Bruno que esto es un aspecto característico del alma del mundo.

A su vez, en Cornelio Agrippa, encontramos el siguiente pasaje: $D e$ occulta philosophia, III, 8 .

\begin{tabular}{|l|l|}
\hline Ipseque Augustinus libro quarto & En el libro cuarto de De civitate Dei, \\
De civitate Dei testatur & Agustín atestigua que el platónico \\
Porphyrium platonicum tres in & Porfirio puso tres personas en Dios: \\
Deo personas posuisse: primam, & la primera, nombrada padre del \\
quam patrem universitatis & universo, la segunda, primera mente \\
appellati, secundam, quam & -e hijo según Macrobio-; la tercera, \\
primam mentem - et filium a a & alma del mundo, a la que Virgilio, a \\
Macrobio dictum; tertiam animam & partir de la opinión de Platón, llama \\
mundi, quam Vergilius ex & espíritu, diciendo: \\
Platonis opinione spiritum vocat, & El espíritu nutre desde dentro, \\
inquiens: & difundida por las arterias \\
Spiritus intus alit totamque & La mente mueve la mole... \\
infusa per artus & Es, por tanto, Dios, como dice Pablo \\
Mens agitat molem... & "de quien todo, en donde todo y por \\
Est igitur Deus, ut inquit Paulus, \\
«a quo omnia, in quo omnia et per \\
quem omnia»..
\end{tabular}

Esta cita nos parece relevante porque no sólo recupera el uso del término spiritus esta vez en relación explícita al alma del mundo, sino que además plantea la relación con el neoplatonismo pagano de Macrobio y un autor afín al neoplatonismo pero claramente cristiano, en Agustín de Hipona, así como la cita directa a Pablo de Tarso ${ }^{87}$ Este conjunto de relaciones de nombres y conceptos con el pasaje virgiliano deja el camino listo para el uso que encontramos en Giordano Bruno.

${ }^{87}$ La referencia es a Epístola a los Colonenses I 16.

Stylos. 2021; 30 (30); pp. 200-240; ISSN: 0327-8859; E-ISSN: 2683-7900 


\section{GIORDANO BRUNO}

Nos detendremos ahora en tres pasajes en que Giordano Bruno hace referencia a Eneida VI 724-727. Intentaremos, en cada caso, dar cuenta de los desplazamientos de sentido que se dan en torno fundamentalmente a los conceptos de anima, mens y spiritus, dando cuenta del contexto del planteo filosófico que plantea en cada caso Bruno.

\subsection{PERSPECTIVAS PITAGÓRICO-VETEROTESTAMENTARIAS EN TORNO A FORMA Y MATERIA}

El primer pasaje que quisiéramos indicar pertenece al segundo diálogo del De la causa, principio e uno. Allí, el personaje Teófilo da cuenta de que todas las cosas, aun cuando no sean animales, están animadas, dado que el espíritu se encuentra en todas las cosas, siendo principio de vida en todo lo que existe. Su interlocutor, Dicson, hace la siguiente observación:

\begin{tabular}{|c|c|}
\hline $\begin{array}{l}\text { ICSONO. - Questo mi par } \\
\text { onforme non solo al senso di } \\
\text { itagora, la cui sentenza recita il } \\
\text { oeta quando dice: } \\
\text { rincipio caelum ac terras } \\
\text { amposque liquentes, } \\
\text { dcentemque globum lunae } \\
\text { itaniaque astra } \\
\text { piritus intus alit, totamque infusa } \\
\text { er arctus } \\
\text { ens agitat molem, totoque se } \\
\text { orpore miscet; } \\
\text { ta ancora al senso del Teologo, che } \\
\text { ice: «Il spirto colma et empie la }\end{array}$ & $\begin{array}{l}\text { doctrina recita el poeta cuando dice: } \\
\text { Principio caelum ac terras campos- } \\
\text { que liquentes, } \\
\text { lucentemque globum lunae Titania- } \\
\text { que astra } \\
\text { spiritus intus alit, totamque infusa } \\
\text { per arctus } \\
\text { mens agitat molem, totque se corpo- } \\
\text { re miscet, } \\
\text { sino también con lo que señala el } \\
\text { teólogo, cuando dice "el espíritu } \\
\text { colma y llena la Tierra, y el que } \\
\text { contiene el todo". Y otro, hablando }\end{array}$ \\
\hline
\end{tabular}

Stylos. 2021; 30 (30); pp. 200-240; ISSN: 0327-8859; E-ISSN: 2683-7900 


\begin{tabular}{|c|c|}
\hline $\begin{array}{l}\text { commercio de la forma con la } \\
\text { ateria e la potenza, dice che è } \\
\text { pravanzata da l'atto e da la }\end{array}$ & $\begin{array}{l}\text { la materia y con la potencia, dice que } \\
\text { es excedida por el acto y por la } \\
\text { forma. }{ }^{89}\end{array}$ \\
\hline
\end{tabular}
forma. $^{88}$

De este pasaje podemos, en principio, destacar tres conexiones del pasaje de Eneida VI 724-727: a) con Pitágoras; b) con las Sagradas Escrituras; ${ }^{90} \mathrm{c}$ ) con el propio pensamiento bruniano, en relación tanto con su doctrina de forma y materia con su doctrina de acto y potencia.

\subsubsection{PROPÓSITO GENERAL DEL DE LA CAUSA, PRINCIPIO E UNO}

Quisiéramos referir brevemente el contexto en que se ubica este pasaje. Este diálogo es el segundo de los seis que compuso Bruno en lengua italiana durante su estadía en Londres entre 1584 y mediados de $1585 .{ }^{91}$ Este en particular es el que aborda más detenidamente la metafísica bruniana, dedicando el segundo diálogo, al que corresponde este pasaje, a la distinción de principio y causa de acuerdo a su concepción. Nos proponemos a continuación dar cuenta de esta caracterización, así como la precisión interna a las causas, a fin de dar cuenta del sentido que tiene la referencia al pasaje de Eneida.

\subsubsection{FORMA Y MATERIA EN BRUNO}

La metafísica bruniana, tal como fue establecida en el contexto de los llamados diálogos londinenses, se vertebra en dos principios: forma y materia. Lo que caracteriza a los principios, a diferencia de las causas, es que los primeros constituyen desde dentro, mientras las segundas lo hacen de forma exter-

${ }^{88}$ De la causa (A 73).

${ }^{89}$ De la causa (2015: 159).

${ }^{90}$ Sabiduría I 7.

${ }^{91}$ De los seis diálogos compuestos por Bruno durante su estadía en Londres, en 1584: La cena delle ceneri; De la causa, principio e uno; Del infinito universo e mondi; Spaccio de la bestia trionfante; en 1585: Degli eroici furori; La cabala del cavallo pegaseo.

Stylos. 2021; 30 (30); pp. 200-240; ISSN: 0327-8859; E-ISSN: 2683-7900 
na. Bruno se refiere a la forma, que llama también alma, no sólo como principio, sino también como causa. Esta distinción entre principio y causa, efectiva en lo que se refiere a los objetos singulares, no es más que una distinción de aspectos en lo que se refiere al intelecto universal (que consiste en el principal modo de actuar del alma del mundo, su causa eficiente), que es a la vez causa y principio. En tanto causa eficiente, no se confunde con sus compuestos y los efectos que produce, pues su ser es diferente de los seres transitorios y corruptibles. Pero en tanto causa intrínseca, en lo que opera, no es un autor exterior a la materia, sino interno. La distinción entre causa y principio resulta, pues, una distinción abstracta, en el sentido de que no se puede realmente distinguir una del otro. La causa es el eficiente desde donde las ideas dirigen el desarrollo de los seres, y el principio, es cómo esos seres son constituidos.

$\mathrm{Al}$ analizar el modo en que opera el alma del mundo, Bruno despliega tres tipos de causas que consisten en aspectos del funcionamiento de un mismo principio: a) la causa eficiente, b) la causa formal y c) la causa final serán los tres aspectos de la actividad de la inteligencia.

a) La causa eficiente (o intelecto universal) consiste para Bruno en la principal forma de actuar del alma del mundo, que modela la materia infundiéndose en ella desde dentro. ${ }^{92}$ Esta causa no es exterior a la naturaleza, sino interior a ésta. En este sentido, Bruno caracteriza al intelecto universal como aquello que "impregna la materia":

Questo intelletto, infondendo e porgendo qualche cosa del suo nella materia: mantenendosi lui quieto et inmobile, produce il tutto (...) lui è quello che impregna la materia di tutte forme, e secondo la raggione, e condizion di quelle, la viene a figurare, formare, intessere: con tanti ordi-

Este intelecto, infundiendo y alojan-
do algo de suyo en la materia, estan-
do él quieto e inmóvil, todo lo pro-
duce (...) él es quien impregna la
materia de todas sus formas, y según
el modo y naturaleza de éstas, confi-
gura, forma y entreteje la materia en
órdenes tan admirables, que en ma-

${ }^{92}$ Esta expresión podemos, desde ya, asimilarla al infusa per artus / mens agitat molem virgiliano, como veremos.

Stylos. 2021; 30 (30); pp. 200-240; ISSN: 0327-8859; E-ISSN: 2683-7900 
ni mirabili, li quali non possono attribuir-si al caso, né ad altro principio che non sa distinguere, et ordinare. ${ }^{93}$

Debemos tener presente que se trata de la abstracción dentro de lo que ha llamado alma del mundo, que actúa ante todo modelando la materia, pero a su vez requerirá una guía para actuar (la causa formal) y un impulso para agotar todas las formas (la causa final). Observemos, también, que el principio de su acción no es el azar, sino lo que llama la vicisitud universal. ${ }^{95}$

Así como no creemos producida sin inteligencia la figura que sabemos grabar en una placa de madera, con mucha más razón debemos reconocer una inteligencia universal que, toda entera en todo, guíe la producción de los seres vivientes, desde la materia seminal y realice, en su plenitud, todos los cambios que se producen en el universo. El intelecto universal llena el universo, lo ilumina y lo guía en la producción de las cosas que lo componen.

En tanto causa eficiente, no es diferente de su efecto. De este modo, como observa Ingegno, el alma del mundo se extiende a todos los niveles del cosmos, eliminando la necesidad de un término superior. ${ }^{96} \mathrm{El}$ intelecto no sólo suscita las cosas de la materia, sino que produce los seres como nosotros imaginamos y concebimos nuestras ideas, pues para él pensar es formar la naturaleza.

b) La causa formal o razón ideal es el conjunto de las ideas del intelecto universal, consideradas antes de ser cosas. Así como un escultor debe imaginar las diversas formas antes de producir las estatuas, el intelecto universal debe

${ }^{93}$ De la causa (A 67-68)

${ }^{94}$ De la causa (2010: 75)

${ }^{95}$ Este concepto, que no podemos abordar aquí por razones de espacio, es fundamental en la filosofía bruniana. Dado que la materia se da en una eterna mutación de formas, esta mutación despliega una vicisitud que lleva a momentos de oscuridad y luz, de mayor racionalidad y de mayor superstición. En el contexto referido, esto nos da cuenta que el proceso del alma del mundo modelando la materia no sigue el azar, sino esta vicisitud universal. Cf. GRANADA (2005).

${ }^{96}$ Cf. INGEGNO (1978: 84-85).

Stylos. 2021; 30 (30); pp. 200-240; ISSN: 0327-8859; E-ISSN: 2683-7900 
poseer en sí las ideas que va a actualizar en el universo. De este modo, consiste en la forma que recibirán los productos del intelecto universal, que preexiste a las cosas que serán hechas.

c) La causa final consiste en la perfección o plenitud de la naturaleza. Para Bruno, la perfección del universo consiste en desplegar todas las formas posibles, para que tengan una existencia actual en las diversas partes del universo. El intelecto se complace en este fin, y jamás deja de suscitar toda clase de especies de la materia. Como observa E. Namer, ${ }^{97}$ la importancia de este concepto de causa final, si bien es enunciado en pocas líneas, radica en que nos da la razón de la variedad natural. Por este motivo, como anota Cuozzo, el mundo físico de la naturaleza manifiesta la totalidad de todo lo que existe. ${ }^{98}$

\subsubsection{CONCEPTO DE ESPÍRITU}

La referencia al pasaje de Eneida se da ${ }^{99}$ en ocasión del intelecto universal. Vemos pues que el spiritus reviste aquí el carácter de alma del mundo, retomando así la interpretación agustiniana de Génesis 1,2, vinculada a Eneida VI 724-727. ${ }^{100}$

Una posible pista acerca de la relación entre los pasajes citados por Bruno podemos encontrarla en In memoriae subsidium de Girolamo Seri-

\footnotetext{
${ }^{97}$ NAMER (1926: 59).

${ }^{98}$ Cf. CuOzzo (2007: 52).

${ }^{99}$ Cabe observar que en dos ocasiones cita este mismo pasaje virgiliano, pero la que nosotros damos es la segunda cita, que es más completa, la primera es parcial y con algún error (quisiéramos aclarar que las diversas citas que damos de distintos autores a veces contienen inexactitudes, fruto de intención o bien de un error, siempre intentamos mantenernos fieles a los términos empleados, aunque contengan errores respecto del original.). Dado que nos interesa el sentido de la cita y su modificación y no, en rigor, el estudio exhaustivo de esta cita consideramos mucho más relevante esta segunda cita.

100 En este sentido, resulta interesante observar que Bruno cita durante su proceso el De Trinitate VII donde Agustín de Hipona afirma que el uso del término "persona" para dirigirse a Dios es fruto de la ineptitud del lenguaje humano para referir a la divinidad. Cf. GISONDI (2020: 73).
}

Stylos. 2021; 30 (30); pp. 200-240; ISSN: 0327-8859; E-ISSN: 2683-7900 
pando (1493-1563), obra que se encuentra en San Giovanni a Carbonara, Nápoles, ciudad donde Bruno tuvo su formación entre 1565 y $1575 .{ }^{101}$ Allí, como nota Giulio Gisondi, encontramos en el capítulo XLIII, en relación a una discusión acerca de la Spiriti Sancti divinitas, dos líneas anotadas al margen con la misma letra que el resto del manuscrito, por lo que correspondería a Seripando, donde puede leerse: "Spiritus Domini ferebatur super aquas / Camposque liquentis, spiritus intus alit". ${ }^{102}$ Así, vemos la unión del pasaje de Sabiduría I 7 y Eneida VI 724-726. La diferencia está, como observa Gisondi, ${ }^{103}$ en que mientras Seripando intenta utilizar esta relación entre pasajes para mostrar que Virgilio se refería al Espíritu Santo, Bruno intenta la operación opuesta: llevar el sentido del texto bíblico más cerca de la fiosofía pitagórica.

\section{2. ¿DISTINCIÓN ANIMA MUNDI Y SPIRITUS UNIVERSORUM? POSIBLE PRIMER DESPLAZAMIENTO}

En Lampas triginta statuarum encontramos a su vez el siguiente pasaje:

XXIV. Imaginandum est hunc esse primum motore immobilem; intellectus enim habet rationem, mens foecunditatem, spiritus autem opera-
XXIV. Debemos imaginar que es el primer motor inmóvil; pues el intelecto tiene razón, la mente, fecundidad, el espíritu, a su vez, operación.

\footnotetext{
${ }^{101}$ Ingresó al convento dominico San Domenico Maggiore en el año 1565, donde permaneció hasta el año 1575, pasando por diversas etapas de la formación que solía darse en ese ambiente: ingresó al convento como profeso, en 1570 fue ordenado subdiácono, y al año siguiente, diácono. Aparentemente, ya en este tiempo daba muestras de la irreverencia que lo caracterizaría, y si bien fue recibido en el Studium de su convento como estudiante formal de teología, fue acusado de negarse a venerar las imágenes de los santos, aceptando únicamente el crucifijo, de hacer malas sugerencias de lectura a un joven novicio y de poseer libros de Erasmo de Rotterdam, un autor prohibido en el catolicismo de la época. Con todo, en 1573 fue ordenado sacerdote, y en 1575 completó sus estudios recibiéndose de teólogo.

102 Cf. Gisondi (2020: 72). La misma relación la establece Bruno en las actas del proceso, tanto el pasaje de la Eneida (referido nuevamente al pitagorismo) con Sabiduría I 7 y suma allí Eclesiastés I 9: "Nihil sub sole novum: quid est? Ipsum quod fuit" (Cf. GISONDI 2020: 73).

${ }^{103}$ Cf. Gisondi (2020: 73).
}

Stylos. 2021; 30 (30); pp. 200-240; ISSN: 0327-8859; E-ISSN: 2683-7900 
tionem. Hic igitur est qui immobilis in se dat cuncta moveri. Unde recte illud Pythagorici: 'spiritus intus alit'. ${ }^{104}$
Es él quien, permaneciendo inmóvil en sí mismo, da movimiento a todo. De allí que con razón ha dicho el [poeta] pitagórico: "el espíritu nutre desde dentro".

Aquí nuevamente vincula a Virgilio con el pitagorismo, así como asocia el espíritu con operación y la mente con fecundidad; ambos, mente y espíritu, pues, dan cuenta del concepto de alma del mundo en Bruno. Esta obra nos permite darle mayor profundidad de sentido a estos conceptos, especialmente al de mente, como veremos en 3.2.2.

\subsubsection{PROPÓSITO DEL LAMPAS TRIGINTA STATUARUM}

Esta obra fue compuesta por Bruno durante su estadía en Wittenberg, y revisada aún durante la etapa de su estadía en Helmstedt, es decir, fue compuesta entre 1585 y 1588, si bien fue publicada póstumamente en 1891. Bruno revisó numerosas veces esta obra, que consiste en una suerte de compendio de su filosofía. Aquí no sólo se da cuenta de su metafísica, sino también del aspecto mnemotécnico y la magia. El objeto del texto es más bien funcionar como un acervo de elementos para poder nutrir sus argumentos que para ser publicado. ${ }^{105}$ De este modo, contamos con un desarrollo de los conceptos filosóficos en relación con su aplicación a otros aspectos de su filosofía. Esta obra se organiza en treinta estatuas, cada una de las cuales se subdivide en treinta campos; de esta manera, cada uno de los aspectos de conocimiento son accesibles de un modo más ordenado.

\footnotetext{
${ }^{104}$ Lampas triginta statuarum (TV 60).

${ }^{105}$ Cf. Ciliberto (2020: 240).
}

Stylos. 2021; 30 (30); pp. 200-240; ISSN: 0327-8859; E-ISSN: 2683-7900 


\subsubsection{CONCEPTO DE MENS FRENTE AL DE SPIRITUS}

El concepto de mens recibe una caracterización que muestra su diferencia respecto al de spiritus. No sólo, como vimos en la cita anterior, asocia a la mente con la fecundidad y al espíritu con la operación, sino que en un pasaje de esta misma obra vincula directamente la noción de mens con comienzo del Evangelio según Juan. ${ }^{106}$ De este modo, establece el lugar de la mente, de un lado, con la producción, y del otro, el espíritu, con la acción, estos aspectos conforman la acción del intelecto universal, a fin de suscitar las diversas mutaciones de la materia.

\subsection{TODAS LAS COSAS ESTÁN LLENAS DE ESPÍRITU: ADOPCIÓN DEL PANTEÍSMO VIRGILIANO COMO EXPRESIÓN DEL ESOTERISMO BRUNIANO}

Nos interesa por último destacar la referencia que realiza aquí Bruno al pasaje virgiliano, a fin de mostrar el nivel al cual llega la influencia del poeta mantuano en el nolano. Tenemos, pues, en De magia:

\begin{tabular}{|l|l|}
\hline In fine illud est firmiter asserendum & En resumen, se ha de afirmar y man- \\
et mente tenendum, quod spiritu, & tener en la mente con firmeza que to- \\
anima, numine, Deo seu divinitate & das las cosas están llenas de espíritu, \\
omnia sunt plena, et intellectus et & alma, numen, Dios o divinidad y que \\
anima ubique totus et tota est, sed & el intelecto y el alma están todo ente- \\
non ubique facit omnia. Hoc insi- & ro por doquier, mas no por todas par- \\
nuavit poeta ex dogmate Pythagori- & ten hacen todas las cosas. Esto lo in- \\
co: & sinuó el poeta, siguiendo la opinión \\
Principio caelum et terras campos- & de Pitágoras: \\
que liquentes & "Desde el principio el espíritu nutre \\
\hline
\end{tabular}

${ }^{106}$ Cf. Lampas triginta statuarum (TV 51): "Imaginare triadem, quae est in dicente verbo, et significato in eo quod dicitur "pater mens est qui dicendo produxit filium seu verbum, et per verbum dictum universa sunt producta"”, y Ev. Según Juan 1, 1-3: "In principio erat Verbum, et Verbum erat apud Deum, et Deus erat Verbum. Hoc erat in principio apud Deum. Omnia per ipsum facta sunt: et sine ipso factum est nihil, quod factum est.".

Stylos. 2021; 30 (30); pp. 200-240; ISSN: 0327-8859; E-ISSN: 2683-7900 


\begin{tabular}{|c|c|}
\hline $\begin{array}{l}\text { Lucentemque globum Lunae Tita- } \\
\text { niaque astra } \\
\text { Spiritus intus alit, totamque infusa } \\
\text { per artus } \\
\text { Mens agitat molem, et totus se cor- } \\
\text { pore miscet } \\
\text { Hinc hominum pecudumque genus } \\
\text { vitaeque volantum } \\
\text { Et quae marmoreo fert monstra sub } \\
\text { aequore pontus. } \\
\text { Idem dicit sensus sacrorum arca- } \\
\text { norum ab omni vulgo receptus, ut in } \\
\text { Psalmo et in libro Sapientiae 'spiri- } \\
\text { tus domini replevit orbem terrarum } \\
\text { et hoc quod continet omnia', et alibi } \\
\text { ccaelum et terram ego impleo'.107 }\end{array}$ & $\begin{array}{l}\text { resplandeciente globo de la Luna y a } \\
\text { los astros Titanios; e infundida por } \\
\text { las articulaciones, la Mente conmue- } \\
\text { ve la mole entera y todo [el espíritu] } \\
\text { se mezcla con el cuerpo. De aquí } \\
\text { [procede] el linaje de hombres, gana- } \\
\text { dos, aves y de los monstruos que el } \\
\text { ponto cría bajo su superficie marmó- } \\
\text { rea." } \\
\text { Lo mismo quiere decir el sentido de } \\
\text { los arcanos sagrados, de todo el } \\
\text { mundo conocido, así en el Psalmo y } \\
\text { en el libro de la Sabiduría: "el espíri- } \\
\text { tu del señor colmó el orbe de las tie- } \\
\text { rras y lo que contiene todas las co- } \\
\text { sas", y en otra parte: "yo lleno el cie- } \\
\text { lo y la tierra". } 108\end{array}$ \\
\hline
\end{tabular}

Encontramos aquí nuevamente la relación entre el pasaje de Eneida con las Sagradas Escrituras y con el pitagorismo. En esta ocasión, el sentido de la cita tiene un aspecto metafísico, pero especialmente un aspecto esotérico: la aplicación del principio del animismo le permite a Bruno dar cuenta de la vinculación en todas las cosas. Luego de ver brevemente el sentido general de este opúsculo, nos detendremos un momento en este aspecto del uso del término para Giordano Bruno.

\footnotetext{
${ }^{107}$ De magia (TV: 434).

${ }^{108}$ De magia (1997: 278-279).
}

Stylos. 2021; 30 (30); pp. 200-240; ISSN: 0327-8859; E-ISSN: 2683-7900 


\subsubsection{PROPÓSITO DEL DE MAGIA}

Esta obra, compuesta durante su estadía en Helmstedt hacia 1590 sin título asignado, ${ }^{109}$ publicada en 1889 por Felice Tocco bajo el titulo De magia. El segundo y tercer apartado de esta obra, titulados "Sobre los vínculos de los espíritus", ${ }^{110}$ y "Sobre la analogía de los espíritus" 111 constituyen sus declaraciones en torno al concepto de spiritus, que hace referencia a los demonios en tanto entidades intermedias entre lo humano y lo divino. Aquello que permanece siempre es el espíritu y la materia, ${ }^{112}$ sin embargo las configuraciones de ambos estas sujetas a continuas alteraciones.

Que los demonios sean entidades intermedias entre lo humano y lo divino data ya del Banquete platónico, ${ }^{113} \mathrm{y}$, por medio del comentario ficiniano a esta obra, llegan a Bruno. ${ }^{114} \mathrm{Y}$ es el propio Bruno quien afirma haber recibido fuentes neoplatónicas para estas consideraciones sobre el espíritu, al iniciar el apartado "De analogia spirituum" afirmando:

Porphyrius, Plotinus et alii Platonici ita spiritibus corpora distribuunt, ut purissimi et optimi, qui etiam Deorum nomine inscribantur, sint ignae substantiae quoad corpus, eamque simplicissimam esse et purissimam. ${ }^{115}$

\section{Porfirio, Plotino y otros platónicos distribuyen los cuerpos entre los es- píritus de manera que los más puros y mejores -a los que incluso puede dárseles el título de dioses-, son sus- tancias ígneas -simplicísimas y purí- simas- en cuanto al cuerpo. ${ }^{116}$}

\footnotetext{
${ }^{109}$ Es menester observar que corresponde al mismo período en el que compuso sus poemas latinos: De triplice minimo et mensura, De monade, numero et figura y De innumerabilibus, immenso et infigurabili, seu De Universo et Mundis.

${ }^{110}$ De magia (TV: 426): "De vinculis spirituum".

${ }^{111}$ De magia (TV: 430): "De analogía spiritum".

112 Así como en 3.1.2 se caracterizaba la realidad en materia y forma o alma, según las categorías del De la causa, principio e uno.

${ }^{113}$ Cf. Banquete 202 d-e.

${ }^{114}$ A través de Ficino le llegan a Bruno no sólo las traducciones y comentarios de Platón y Plotino, sino también el De daemonibus de Pseudo Miguel Psellos, obra que aporta clasificaciones de demonios que Bruno utiliza en estos pasajes.

${ }^{115}$ De magia, (TV 430).

${ }^{116}$ De magia, (1997: 274).
}

Stylos. 2021; 30 (30); pp. 200-240; ISSN: 0327-8859; E-ISSN: 2683-7900 
En la obra cita también entre sus fuentes a Orígenes, Basilio, Pitágoras. ${ }^{117}$ De este modo, se inscribe en una tradición neoplatónica que constituía una jerarquía ontológica. Esta debe ser presupuesta en esta concepción a la hora de considerar la posibilidad de realización de la magia.

\subsubsection{METAFÍSICA Y ESOTERISMO}

En relación a la concepción bruniana de spiritus, consideramos que la siguiente cita permitirá clarificar su uso:

mox ascendit animal per animum ad sensus, per sensus in mixta, per mixta in elementa, per haec in daemones, per hos [in elementa, per haec] in astra, per ipsa in Deos incorpóreos seu aethereae substantiae seu corporeitatis, per hos in animam mundi seu spiritum universo, per hunc in contemplationem unius simplicissimi optimi maximi incorporei, absoluti, sibi sufficientis. ${ }^{118}$
A continuación el animal asciende por el alma a los sentidos, por los sentidos a los mixtos, por los mixtos a los elementos, por éstos a los demonios, por éstos a los astros, por ellos a los dioses incorpóreos o de sustancia o corporeidad etérea, por éstos al alma del mundo o espíritu del universo, por éste a la contemplación de la unidad simplicísima óptima máxima incorpórea, absoluta, autosuficiente. ${ }^{119}$

En la perspectiva bruniana aquí desplegada quisiéramos sólo destacar dos aspectos que consideramos centrales: a) la existencia de una escala de la naturaleza, ${ }^{120}$ presupuesto necesario para este ascenso y descenso y para po-

\footnotetext{
117 Giovanozzi cita las siguientes obras como posibles fuentes: De abstinentia de Porfirio, De sacrificio et magia, así como los excerpta al Commentarium in Alcibiadem Primum Platonis de Proclo, y el De daemonibus de Psello. Cf. Giovanozzi (2000: 81).

${ }_{118}$ De magia (TV 402).

${ }^{119}$ De magia (1997: 252-253).

${ }^{120}$ Cabe la consideración de que este no es, como podría parecer, un concepto contradictorio con la metafísica de la unidad infinita propuesta por Bruno. Es decir, la no existencia de un
}

Stylos. 2021; 30 (30); pp. 200-240; ISSN: 0327-8859; E-ISSN: 2683-7900 
sibilitar la vinculación de las entidades en el ámbito mágico; y b) la explícita identificación entre "alma del mundo" y "espíritu del universo", con lo cual muestra que efectivamente el spiritus juega en lo esotérico el rol que el alma del mundo tenía en la fundamentación metafísica.

En el contexto de la cosmología bruniana podemos percibir que en realidad no tiene sentido dar cuenta de una distinción entre lo terrenal y celestial, dado que considera que la materia es homogénea en el universo. El spiritus que vincula todo en el universo no es otra cosa que el alma del mundo, que en De la causa, principio e uno, Bruno llamaba la facultad principal del intelecto universal, que vivifica todo desde dentro. En este sentido podemos ver una reinterpretación de la magia en términos de su concepción metafísica y cosmológica, por lo que vemos que no asume al nivel que dice Yates los elementos de la tradición de Ficino y Agrippa, si bien los recibe, pero sólo en el entorno de una metafísica de raigambre neoplatónica, con fuertes resonancias del pensamiento de Nicolás de Cusa, así como del copernicanismo. ${ }^{121}$ El pensamiento de Bruno, además de su vitalismo, se caracte-

mundo sublunar y uno supra-lunar no impide una escala de la naturaleza, en tanto Bruno da cuenta de que todo tiene capacidad para todo, pero no todo se actualiza del mismo modo.

${ }^{121} \mathrm{Si}$ bien el pensamiento de Bruno no se reduce a la magia, tampoco la excluye. Es fundamental para entender la manera en que Bruno entiende los vínculos naturales y por tanto, es un medio clave para tener una comprensión omni-abarcadora de su filosofía natural. Podríamos, en este sentido, notar tres momentos en la recepción del De magia: 1) en 1889, Tocco y Vitelli, a cargo de la primera edición crítica de la obra Latina de Bruno, consideraron que era una obra menor y para no darle importancia, dado que no participaba de concepciones tan modernas como las obras de índole cosmológica; 2) en 1964 Frances Yates publicó su obra Giordano Bruno and the Hermetic Tradition, que propuso una concepción de Bruno como primordialmente mago: de este modo, el antiguamente celebrado "atomismo" bruniano de sus obras latinas, nacería, por ejemplo, de su concepción de spiritus en De magia; 3) en 1999 Hilary Gatti fue propulsor de una concepción renovadora de esta obra: el lugar de la magia no debe ser menospreciado en la obra de Bruno, como acertadamente mostró Yates, pero tampoco debe quitar valor a la obra de índole metafísica y cosmológica que desarrolló paralelamente. De este modo, Gatti ha mostrado que muchas de las interpretaciones que Yates hizo de los gráficos de Bruno, que interpretaba casi exclusivamente en términos de diagramas herméticos, tenían en realidad un sentido de índole filosófica, matemática o cosmológica. En este sentido, Gatti hace notar lo exagerado de la interpretación de Yates, quien dice que Bruno es un reaccionario que quiere hacer retroceder el diagrama copernicano en el contexto de la mathesis. Siendo la mathesis uno de los cuatro rectores, mientras Agrippa afirmaba que los

Stylos. 2021; 30 (30); pp. 200-240; ISSN: 0327-8859; E-ISSN: 2683-7900 
riza por la concepción de una cierta organicidad del universo, como llama Spruit, la idea de una schala naturae que estructura el universo jerárquicamente. ${ }^{122}$ Es todo este entramado el que consideramos da forma al pensamiento bruniano, en el que la magia ocupa un lugar importantísimo, pero no preeminente.

Ahora bien, Bruno no acepta la distinción entre mundo sublunar y supralunar, como hacían los peripatéticos, ni la distinción entre un mundo inteligible y uno sensible, como los platónicos. Para Bruno, el universo es uno e infinito, con un espacio homogéneo ¿Cómo podía, entonces, sustentar una concepción esotérica en la que los vínculos de las cosas por medio del espíritu que se difunde en todo el universo se ven afectadas? Observa Canone que, si bien Bruno rechaza cualquier jerarquía ontológica en el universo, esta oposición a una "escalera de la naturaleza" lo lleva a cambiar el enfoque: esta jerarquía no se da ontológicamente, sino gnoseológicamente: se da en la capacidad que tienen los humanos por medio de los sentidos y la imaginación para, por medio del lenguaje, realizar los vínculos. En este sentido, afirma Canone, las operaciones mágicas se sustentan en el concepto de anima mundi y de un espíritu difundido por todo el universo. ${ }^{123}$

\section{CONCLUSIONES}

Hemos visto en este trabajo la presentación de una concepción en Virgilio, de características que, si bien inferidas, parecen estar bastante determinadas: un panteísmo de origen órfico-pitagórico-estoico, que en manos del mantuano recibe un despliegue en el contexto del discurso de Anquises a Eneas en Eneida VI 724-727 donde se incorpora el aspecto del espíritu, la mente, la mole y el gran cuerpo. Además de los elementos explícitos de este discurso, señalamos numerosos elementos implícitos a los tres pasajes virgilianos abordados: así, algunos vislumbraron cierto proto-monoteísmo en Eneida VI

tres guías en la religión eran Amor, Esperanza y Fe, para Bruno eran Amor, Arte, Mathesis y Magia (YATES 1964: 272).

${ }^{122}$ Cf. SPRUIT (2002: 248).

${ }^{123}$ Cf. CANONE (2004: 153).

Stylos. 2021; 30 (30); pp. 200-240; ISSN: 0327-8859; E-ISSN: 2683-7900 
v. $749,{ }^{124}$ así como en Geórgicas IV $721 ;{ }^{125}$ hemos visto que los términos mens, spiritus serán de gran peso para la discusión posterior, así como las inclinaciones panteístas, que veíamos muy marcadamente en la tercera égloga.

La recepción del pasaje de Eneida VI desde Minucio Felix, pasando por Macrobio, Servio, los autores de la Patrística hasta el Renacimiento nos permite ver las reformulaciones diversas que llevan a la constitución del dualismo alma/materia, conduciendo a la transformación del panteísmo original en diversas doctrinas teñidas de neoplatonismo con inflexiones cristianizantes en muchos casos. ${ }^{126}$

En manos de Bruno, este pasaje es retomado en numerosas ocasiones a manera de dar cuenta de su propia visión respecto de la participación del alma del mundo en la eterna mutación de la materia. Y será la noción de espíritu la que recibirá en Bruno el lugar del alma del mundo en el contexto de sus escritos esotéricos, lo cual nos permite constatar la final vinculación con este pasaje. ${ }^{127}$

\section{BIBLIOGRAFÍA}

ARATO, Fenómenos, Madrid: Gredos, 1993.

BRUnO, G., De la causa, principio e uno, a cura di G. Aquilecchia, Torino: Einaudi (A), 1973.

${ }^{124}$ Cf. Eneida VI 749: "Lethaeum ad fluvium deus evocat agmine magno".

${ }^{125}$ Cf. Geórgicas IV 721: "aetherios dixere; deum namque ire per omnes".

${ }^{126}$ La referencia a Seripando que citamos de la obra de Gisondi nos parece clave para comprender la conexión que Bruno realiza entre Sabiduría I 7, un texto de índole teológica, y Eneida VI 724-727. Esto no implica, desde ya, obviar los cambios de sentido que encontramos en los pasajes referidos de Ficino y Agrippa.

${ }^{127}$ La extensión de esta investigación nos priva de realizar un estudio más profundo en torno al sentido que tiene este pasaje en otros autores que consideramos sumamente relevante. Es una discusión actual, como lo muestran los trabajos de LOTTI (2019) y GISONDI (2020), y esperamos que en los próximos años pueda llegarse a investigaciones que clarifiquen aún más la situación de este pasaje tan oscuro como fascinante.

Stylos. 2021; 30 (30); pp. 200-240; ISSN: 0327-8859; E-ISSN: 2683-7900 
BRUNO, G., Opera latine conscripta, publicis sumptibus edita, recensebat [F. Fiorentino F. Tocco, H. Vitelli, V. Imbriani, C. M. Tallarigo], 3 volumi in 8 parti: Neapoli-Florentiae (=F; TV; IT), 1879-1891. la causa, principio e uno, a cura di G. Aquilecchia, Torino: Einaudi (A), 1973.

BRUno, G, Mundo, magia, memoria, Madrid: Biblioteca Nueva, 1997.

BRUno, G. De la causa, principio y uno, Buenos Aires: Losada, 2010.

HoMERo, Ilíada, Madrid: Gredos, 2006.

LUCRECIO, Acerca de la naturaleza de las cosas, Buenos Aires: Las Cuarenta, 2019.

MACROBIO, Comentario al «Sueño de Escipión», Madrid: Gredos, 2006.

MAURUS SERVIUS HonORATUS [SERVIUS], In Vergilii Aeneidem commentarii, Georgius Thilo, Hermannus Hagen (ed.), 3 vol., Lipsiae in aedibus B. G. Teubneri, 1881-1902.

TEOCRITO, Bucólicos griegos, Madrid: Gredos, 1986.

AdLer, E. Vergil's Empire. Political Thought in the Aeneid, LanhamBoulder-New York-Oxford: Rowman \& Littlefield Publishers, Inc., 2003.

AlBANESE, L. "Bruno, Virgilio e lo Spirito Santo", Bruniana \& Campanelliana 2000 6-1: 181-188.

ALdEn SMith, R. Virgil, West Sussex: Wiley-Blackwell, 2011.

BAUZA, H. "Virgilio y el orfismo", Nova tellus 2015 32-2: 215-269.

BERNABE, A. Textos órficos y filosofía presocrática. Materiales para una comparación, Madrid: Trotta, 2004.

Bremmer, J. " The Golden Bough: Orphic, Eleusinian, and HellenisticJewish Sources of Virgil's Underworld in Aeneid VI", Kernos. Revue internationale et pluridisciplinaire de religion grecque antique, 2009 22: 183-208.

BREMMER, J. Initiation into the Mysteries of the Ancient World, Berlin/Boston: Walter de Gruyter GmbH, 2014.

CANONE, E. "Giordano Bruno: Hermeticism and Magic in Wisdom's Mirror", Bruniana \& Campanelliana, 2004 10-1: 151- !55.

CiLIBERTO, M. Il sapiente furore. Vita di Giordano Bruno, Milano: Adoplhi, 2020.

Stylos. 2021; 30 (30); pp. 200-240; ISSN: 0327-8859; E-ISSN: 2683-7900 
COURCELlE, P. Lecteurs païens et lecteurs chrétiens de l'Éneide, Paris: Institut de France, Mémoires de l'Académie des Inscriptions et BellesLettres. Nouvelle Série. IV, 1984.

Cumont, F. " Comment Plotin détourna Porphyre du suicide", Revue des Études Grecques, 191932 : 113-120.

Cumont, F. Lux perpetua, Paris: Libraire Orientaliste Paul Geuthner, 1949.

CuOzzo, G. Dal panteismo ontoteologico alla teologia infinitesimal. Con inedita di Vincenzo Gioberti su Giordano Bruno e Nicola Cusano, Torino: Nino Aragno Editore, 2007.

GatTI, H. Giordano Bruno e la scienza del Rinascimento, Milano: Raffaello Cortina Editore, 2001 [1999].

GieseCKe, A. Atoms, Ataraxy, and Allusion. Cross-generic Imitation of De Rerum Natura in Early Augustan Poetry, Zürich-New York: Georg Olms Verlag Hildesheim, 2000.

GiovanNOZZI, D. "«Porphyrius, Plotinus et alii platonici». Echi neoplatonici nella demonología bruniana", Bruniana \& Campanelliana, 2000 6-1: 79-103.

GISONDI, G. «Profonda magia». Vincolo, natura e politica in Giordano Bruno, Napoli: Istituto Italiano per gli Studi Filosofici, 2020.

GRANADA, M. A. "«Virgilio y la theologia poetica en el humanism y en el platonismo del Renacimiento" en Faventia, 1983 5-1: 41-64. https://raco.cat/index.php/Faventia/article/view/49778 [Consulta: 2707-2021].

GranADA, M. A. "Giordano Bruno y América: de la crítica de la colonialización a la crítica del cristianismo", 197-269. En: M. A. Granada, Giordano Bruno. Universo infinito, union con Dios, perfección del hombre, Barcelona: Herder, 2002.

GRANADA, M. A. "Universo infinito, vicissitudine y «verdadera moralidad»”, 215-242. En: M. A. Granada, La reivindicación de la filosofía en Giordano Bruno, Barcelona: Herder, 2005.

Gransden, K. W. Virgil. The Aeneid, Cambridge: Cambridge University Press, 2004.

GREGORY, T. "Anima del mondo", Bruniana \& Campanelliana, 2006 12-2: $525-535$.

Stylos. 2021; 30 (30); pp. 200-240; ISSN: 0327-8859; E-ISSN: 2683-7900 
HARDIE, P. Virgi's Aeneid. Comos and imperium, Oxford: Oxford University Press, 1986.

HARRISON, S. J. Generic enrichment in Vergil \& Horace, Oxford: Oxford University Press, 2007.

Horsfall, N. Virgil, Aeneid 6. A Commentary, Berlin/Boston: De Gruyter, 2013.

Horsfall, N. The Epic Distilled. Studies in the Composition of the Aeneid, Oxford: Oxford University Press, 2016.

INGBERG, P. "Introducción", 7-31. En: Virgilio, Bucólicas, Buenos Aires: Losada, 2004.

InGEGNO, A. Cosmologia e filosofia nel pensiero di Giordano Bruno, Firenze: La Nuova Italia, 1978.

JAMES, A. W. "The Zeus Hymns of Cleanthes and Aratus", Antichthon, 1972 $628-38$.

Kraggerud, E. Critica. Textual Issues in Horace, Ennius, Vergil and Other Authors, London-New York: Routledge, 2021.

LOTTI, B. "Spiritus intus alit. La fortuna di un topos virgiliano nel pensiero britannico d'età moderna", 141-164. En: L. Bianchi, A. del Prete y G. Paganini, Cartesianisi, scetticismi, filosofia moderna. Studi per Carlo Borghero, Roma: Le Lettere, 2019.

MACKENZIE, T. "Georgica and Orphica: The Georgics in the Context of Orphic Poetry and Religion", 67-78. En: B. Xinyue y N. Freer, Reflections and new perspectives on Virgil's Georgics, LondonNew York: Bloomsbury Academic, 2019.

MAURY, P. "Le secret de Virgile et l'architecture des Bucoliques", Lettres d'Humanité, 1944 3: 71-147.

MORTON BRAUND, S. "Virgil and the cosmos: religious and philosophical ideas", 204-221. En: Ch. Martindale (ed.), The Cambridge Companion to Virgil, Cambridge: Cambridge University Press, 1997.

Mras, K. "Macrobius' Kommentar zu Ciceros Somnium. Ein Beitrag zur Geistesgechichte des 5. Jahrhunderts n. Chr.", Sitzungsberichte der preussischen Akademie der Wissenschaften. Philosophisch-historische Klasse, 1933 6: 232-288.

Stylos. 2021; 30 (30); pp. 200-240; ISSN: 0327-8859; E-ISSN: 2683-7900 
NAMER, É. Les aspects de Dieu dans la philosophie de Giordano Bruno. Thèse pour le doctorat en philosophie de l'Université de Paris, Paris: Libraire Félix Alcan, 1926.

Norden, E. P. Vergilius Maro Aeneis Buch VI, Stuttgart: B. G. Teubner, 1976.

SAUNDERS, T. Bucolic Ecology. Virgil's Eclogues and the Environmental Literary Tradition, London-New Delhi-New York-Sidney: Bloomsbury, 2008.

SEgURA RAmOs, B. "Introducción", 7-20. En: Virgilio, Bucólicas - Geórgicas, Madrid: Alianza Editorial, 1997.

SNELl, B. The Discovery of the Mind. The Greek Origins of European Thought, Massachusetts: Harvard University Press, 1953.

SPRUIT, L. "Giordano Bruno and Astrology", 229-249. En: H. Gatti (ed.), Giordano Bruno. Philosopher of the Renaissance, London-New York: Routledge, 2002.

WiLliams, R. D. "The Sixth Book of the 'Aeneid"”, Greece \& Rome. Second Series, 1964 11-1: 48-63.

YATES, F. Giordano Bruno and the Hermetic Tradition, London: Routledge and Keegan Paul, 1964.

Stylos. 2021; 30 (30); pp. 200-240; ISSN: 0327-8859; E-ISSN: 2683-7900 